\title{
FIELD AND LABORATORY TESTING OF TIME DOMAIN REFLECTOMETRY CABLES FOR LANDSLIDE MONITORING
}

\author{
M.sc. Davide Brambilla ${ }^{1}$
}

M.sc. Laura Longoni ${ }^{1}$

Assoc. Prof. Monica Papini ${ }^{1}$

${ }^{1}$ Politecnico di Milano, Italy

\begin{abstract}
Due to the large number of landslides and mass movements that hit Italy every year, mitigation and monitoring of critical situations arise as crucial aspects of engineering geology. Time Domain Reflectometry (TDR) is a monitoring technique that could integrate or even substitute inclinometer, a standard tool to measure slope displacements. Even if the use of TDR cables is not extremely recent in geotechnical monitoring, it still poses interesting challenges in sensor tuning and results interpretation. The work presented here has the objective to find a quantitative correlation between TDR response and cable deformation. Two approaches have been followed: laboratory and in situ tests. Laboratory testing aims at finding a relationship between deformation type and TDR response; in situ testing features a net of TDR cables coupled to inclinometers. Our work aims at showing that TDR can effectively replace inclinometer sounding if a period of tuning with reference measures is available.
\end{abstract}

Keywords: TDR, landslide, monitoring, inclinometer

\section{INTRODUCTION}

Nowadays hydrogeological risks are for sure one of the most threatening natural hazards, also due to the climate change that increases the number of extreme meteorological events, causing more floods and landslides than in the past. Due to the catastrophic and complex features of each event, we should focus our attention on disasters prevention, both in terms of emergency planning and active monitoring systems.

\section{MONITORING INSTRUMENTS}

The standard tool for deep movements monitoring is inclinometer. Its capability to measure both depth of the sliding surface and movements direction with high precision makes this tool absolutely reliable and useful to monitor and investigate landslides. Nevertheless, inclinometer soundings have some limitations concerning their use and lifetime; boreholes have to be equipped with a dedicated rail to guide the tool and can become unusable if displacement of the landslide body partially crushes the rail tube. 


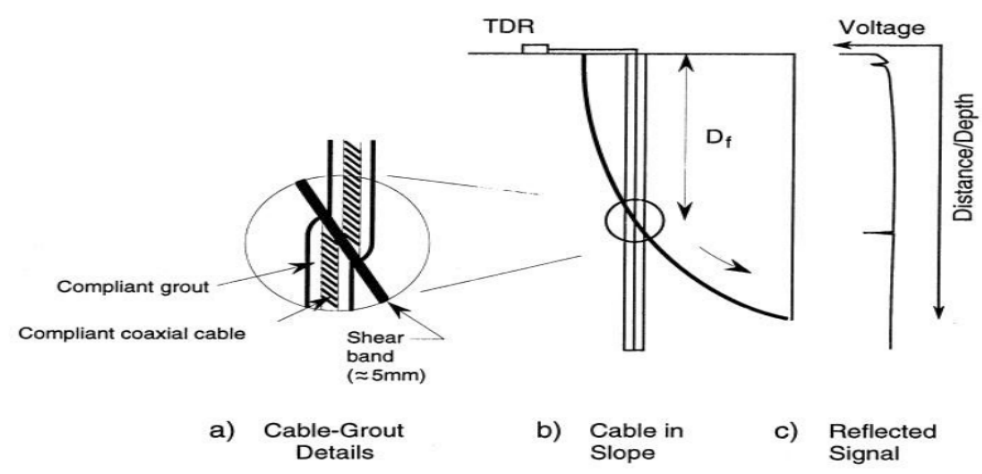

Figure 1. Details of TDR cable installation and signal reading after deformation (after Dowding et al 2003 [1])

Therefore, inclinometer tubes have a limited life span covering few years or, alternatively, few centimetres of displacement. In the last decades, Time Domain Reflectometry (TDR) was tested as a new technology to tackle these drawbacks. This technique relies on recording of electromagnetic signals which are reflected wherever the coaxial cable they are propagating in is deformed.

\section{TDR TECHNIQUE}

TDR technique was born at the beginning of 20th century when it was studied and introduced to localize faults in telecommunications cables (Rohrig 1931 [2]). From the seventies, TDR was used to measure soil water content in agriculture to tune irrigation schemes (Dalton et al 1984 [3]; Dalton 1992 [4]) and also to monitor unstable rock slopes for mining purposes (Dowding et al 1988 [5]). Examples of such applications can be also found in Dowding et al 1989 [6], Lord et al (1991) [7], Aston et al (1994) [8], and Dowding \& Huang 1994 [9]. TDR monitoring of loose soil slopes is more difficult because of the low stiffness of terrain. This creates thick shear bands instead of sharp sliding planes that are usually mapped and investigated in detail with other techniques (Longoni et al 2012 [10],Scaioni et al 2014 [11]).

TDR working principle is similar to the radar one: echo-meter sends a voltage pulse along a coaxial cable deployed into the subsurface; whenever the pulse comes across an impedance variation due to cable deformation, part of the signal is reflected back (Kane \& Beck 1996 [12], Kane \& Beck 1999 [13], Kane 2000 [14]). The shape and magnitude of reflection are associated the kind and size of cable deformation, as illustrated in Figure 1. Location of the fault is measured knowing pulse velocity along the cable and time elapsed between signal transmission and reflection recording.

The main advantages of TDR over classical inclinometer are related to three key aspects: costs, real-time monitoring and durability. First, as far as costs are concerned, cables are inexpensive when compared to inclinometric tubes and the price of the controlling electronic circuitry is comparable to an inclinometer. Second, contrary to inclinometer logging, TDR offers the possibility to monitor deformations continuously, with dense temporal and spatial sampling frequency. Finally, TDR cables stand larger 


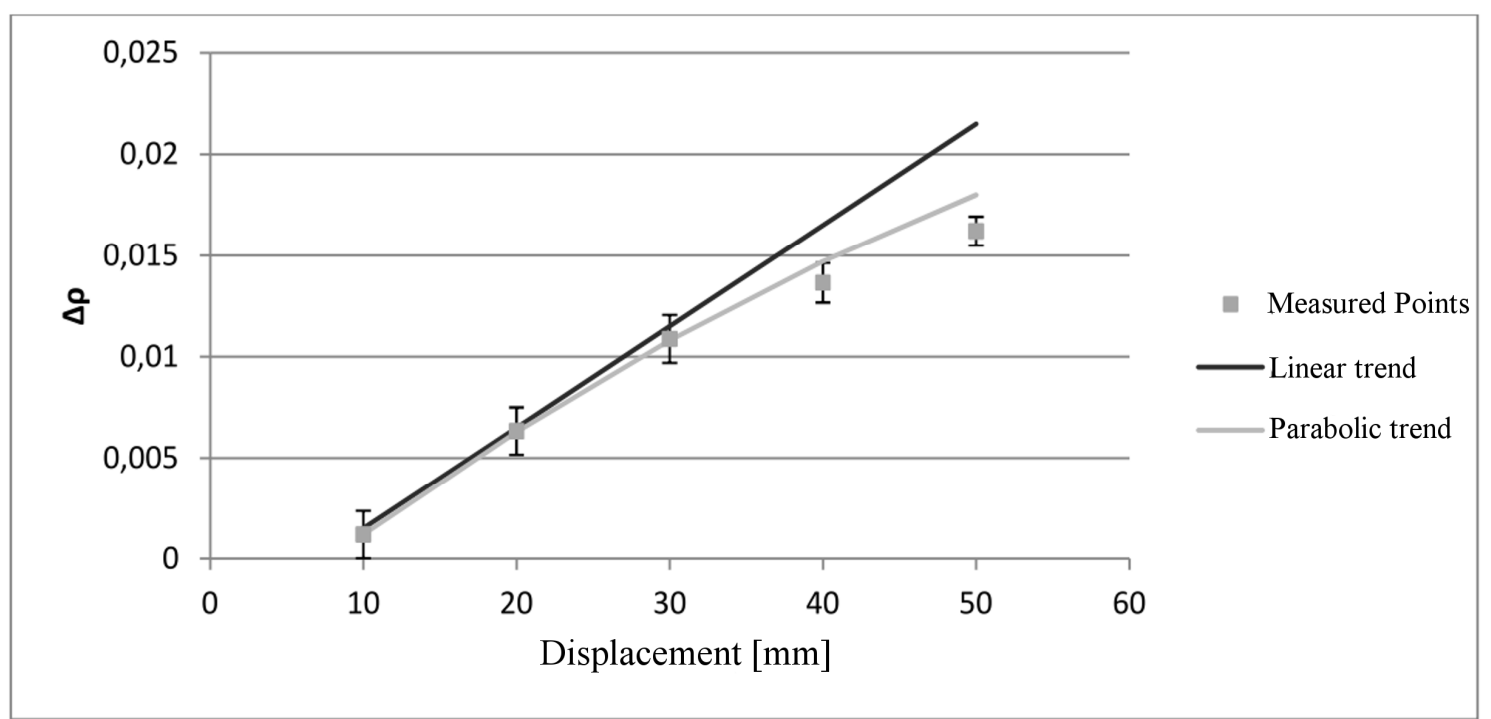

Figure 2. $8.9 \mathrm{~mm}$ coaxial cable. Reflection coefficients (grey dots) with standard deviation (black bars) measured for different displacements along with linear and parabolic trend lines.

deformations than inclinometric tubes do. This may be particularly useful for large slow-moving landslides because it allows nonstop monitoring of displacements for longer periods, during which excessive strain may cause inclinometric tube breakage. For these grounds, TDR technique shows good potentials to be coupled or even to replace inclinometers. Nevertheless it is also affected by an important downside, that is displacement measurement is qualitative. The purpose of this work is to test TDR, both in laboratory and in situ, in order to find possible solutions to overcome this limitation and improve TDR effectiveness.

\section{LABORATORY TEST}

As a first step, a laboratory comparison session was performed to link reflected amplitude value to the applied displacement. Lab testing is particularly useful because each parameter that could have an influence on final result can be controlled and because a particular test can be repeated several times in standard conditions. The first aim was to find a relation between the reflected signal measured by the echo-meter and the real deformation applied to the cable. We paid attention to the parameters that can affect the result, namely, the kind of cable (coaxial cables with three different diameters were tested: $5.8,8.9,10.3 \mathrm{~mm}$ ), the thickness of shear band simulated and environmental conditions such as temperature. First aspect to be considered is the variability of reflection coefficient, that, on undisturbed cables, slightly changes at different times because of micro variations of impedance, creating a threshold, proportional to distance, under which is not possible to distinguish between noise and a real reflection. In addition to this effect, signal attenuation is considered and a parabolic trend for attenuation was initially assumed and later confirmed by the tests. The knowledge of these two parameters is the background for any following test.A literature survey concerning the most common type of cable deformation pointed out that TDR cables usually undergo shear deformation in thin bands of about $30 \mathrm{~mm}$. This measure is due to the cracking of the concrete grout that keeps the cable fixed in the borehole. Cables were tested for shear different deformations between 0 and $60 \mathrm{~mm}$ with a $2 \mathrm{~mm}$ 
$15^{\text {th }}$ International SGEM GeoConference on science and technologies in geology, exploration and mining.

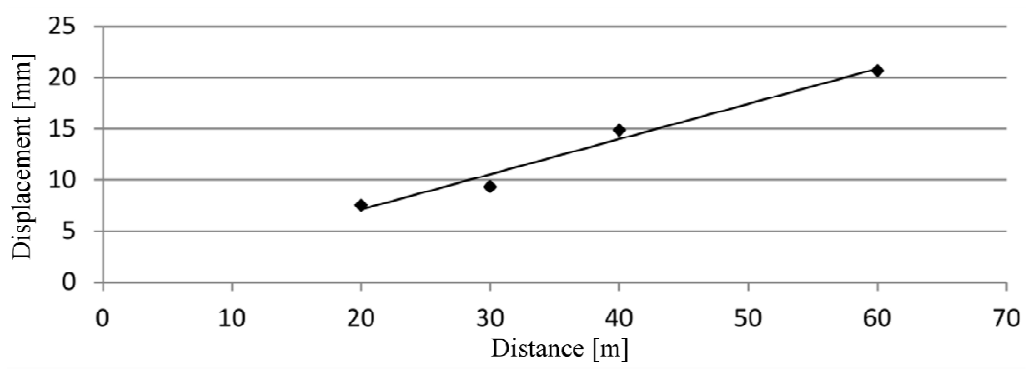

Figure 3. Minimum detectable displacement as a function of distance.

step, at different distances from the beginning of the cable. The tests revealed a clear relation between reflection amplitude and the deformation value, as expected, but the relation between the two parameters is parabolic and not linear unlike what is commonly found in the literature (O'Connor \& Dowding 1999 [15]). A parabolic function better interpolates the measured points (Fig. 2) and thus must be assumed when dealing with real data collected in the field. Similar results were obtained for all the three tested cables. Moreover, the distance from the echo-meter strongly influences the amplitude of the reflected signal attenuation can be modelled and compensated to allow for proper deformation evaluation at any distance along the cable. Finally, an analysis about the smallest detectable displacement was also accomplished. TDR measuring capability spans over a range, whose upper limit is related to the maximum deformation up to cable breaking, while minimum deformation depends on Signal-to-Noise Ratio (SNR) and signal attenuation. Hence TDR sensitivity is higher for close-range deformations. Figure 3 illustrates the least measurable displacement, for a particular cable, as a function of the distance from the echo-meter.

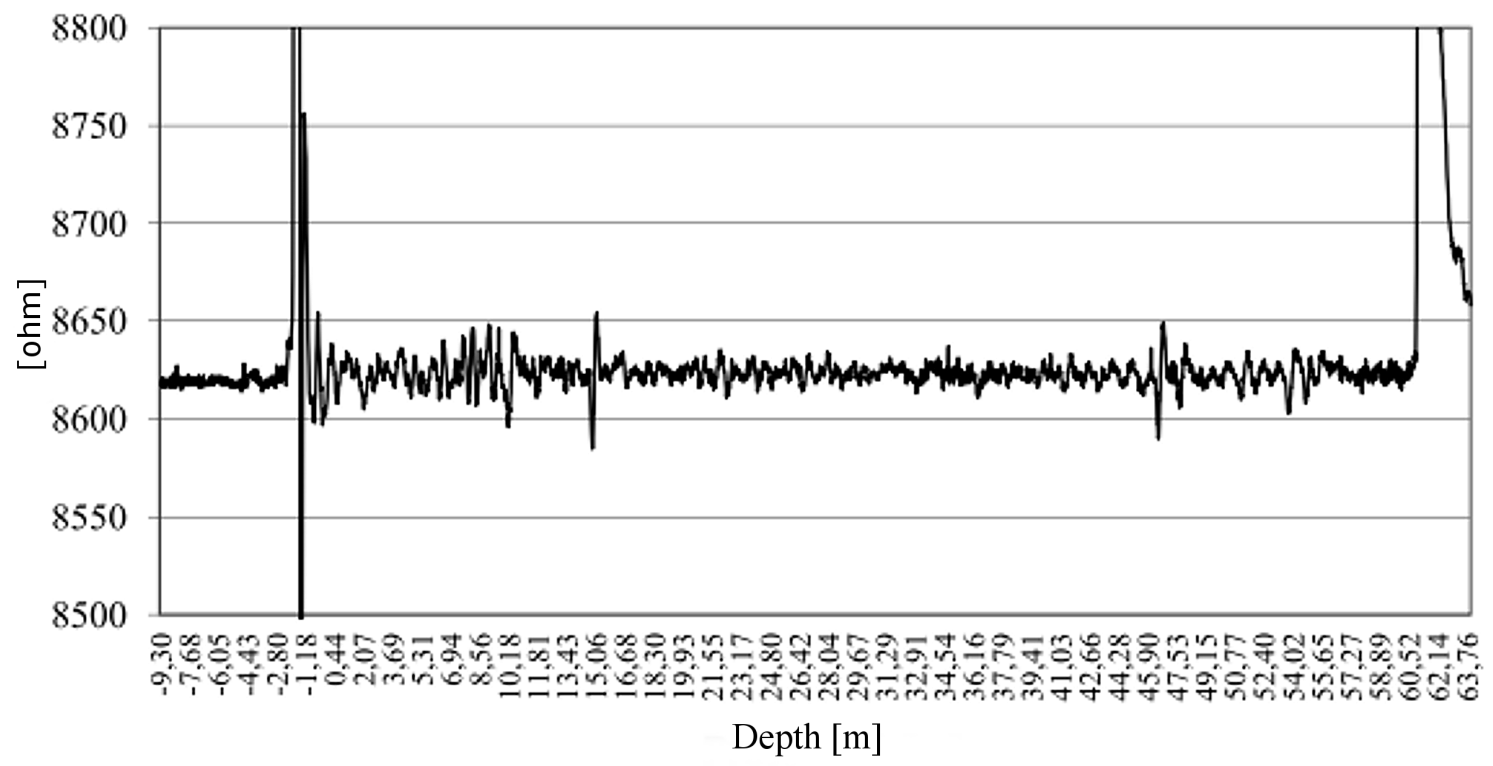

Figure 4. Example of TDR signal reflection along the cable, values are in ohm. 

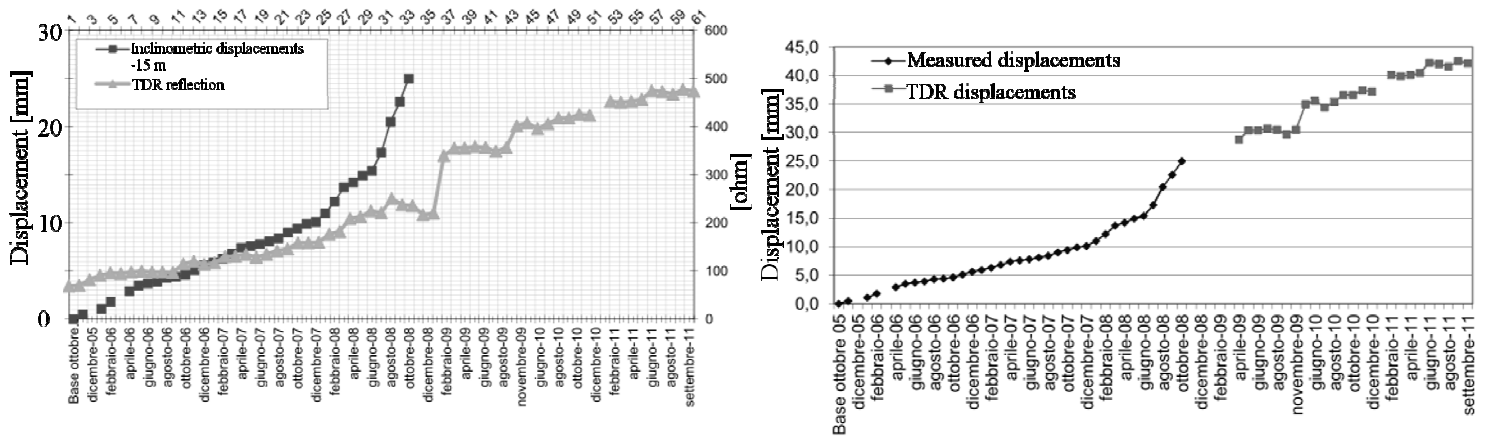

Figure 5. Comparison between TDR and Inclinometric measurements.

\section{IN SITU TESTING}

Inclinometers and TDR cables were jointly deployed in a test site to validate the approach and to make the most of the previous laboratory test experience.

The test site cannot be revealed because of non-disclosure agreement. For the purpose of this paper, it can be stated that the investigated area features a large shallow slope movement, with a medium deepness of $15 \backslash 25$ metres, monitored by a set of four inclinometers coupled to just as many TDR cables of the same kind $(8.9 \mathrm{~mm})$ of the ones tested in laboratory. Field campaign involved monthly measurements of all the tubes from October 2005 up to the tube cracking, while TDR readings continued till September 2011 on a monthly basis. Thus, a good database is available for tuning and testing TDR surveying with respect to inclinometer logging. The comparison between inclinometers and TDR cables data has been focused on the most deformed point of the tube, while TDR values have been supplied as ohm resistance.

Figure 4 shows an example of a TDR monthly measure. High amplitude reflections at -1 $\mathrm{m}$ and $60 \mathrm{~m}$ depth are due to the beginning and to the end of the cable respectively Negative depths indicated on the $\mathrm{x}$-axis have no physical meaning and are due to a link cable installed between the measuring device and the grouted cable, while $0 \mathrm{~m}$ indicates the point where the cable intersect terrain surface. The analysis of the signal is done on the full profile and the reflection at the maximum deformation point, found with inclinometer, is taken into account; the magnitude of the reflection is defined as the peak-to-peak signal amplitude and the variation of the reflection magnitude in time with respect to the first measure is plotted.

Two graphs were elaborated (Figure 5), first one shows the displacement at $15 \mathrm{~m}$ depth and the associated TDR recordings. From the two readings a relation between TDR signal and displacements is deducted and used to infer displacements after inclinometer breakage occurred in October. Figure 6 shows another example from the same site.

\section{DISCUSSION}

In all the four TDR cables deployed at the test site, a clear relationship between measured displacements and reflection amplitude was identified. In addition, TDR sounding was able to locate the depth of the sliding surface with an accuracy of about 1 $\mathrm{cm}$. The coupling of TDR and inclinometric logging allowed for a proper tuning of the reflection law that was essential to make consistent hypothesis on displacements after inclinometer tube breakage. It has to be mentioned that, during data processing, some 
$15^{\text {th }}$ International SGEM GeoConference on science and technologies in geology, exploration and mining.

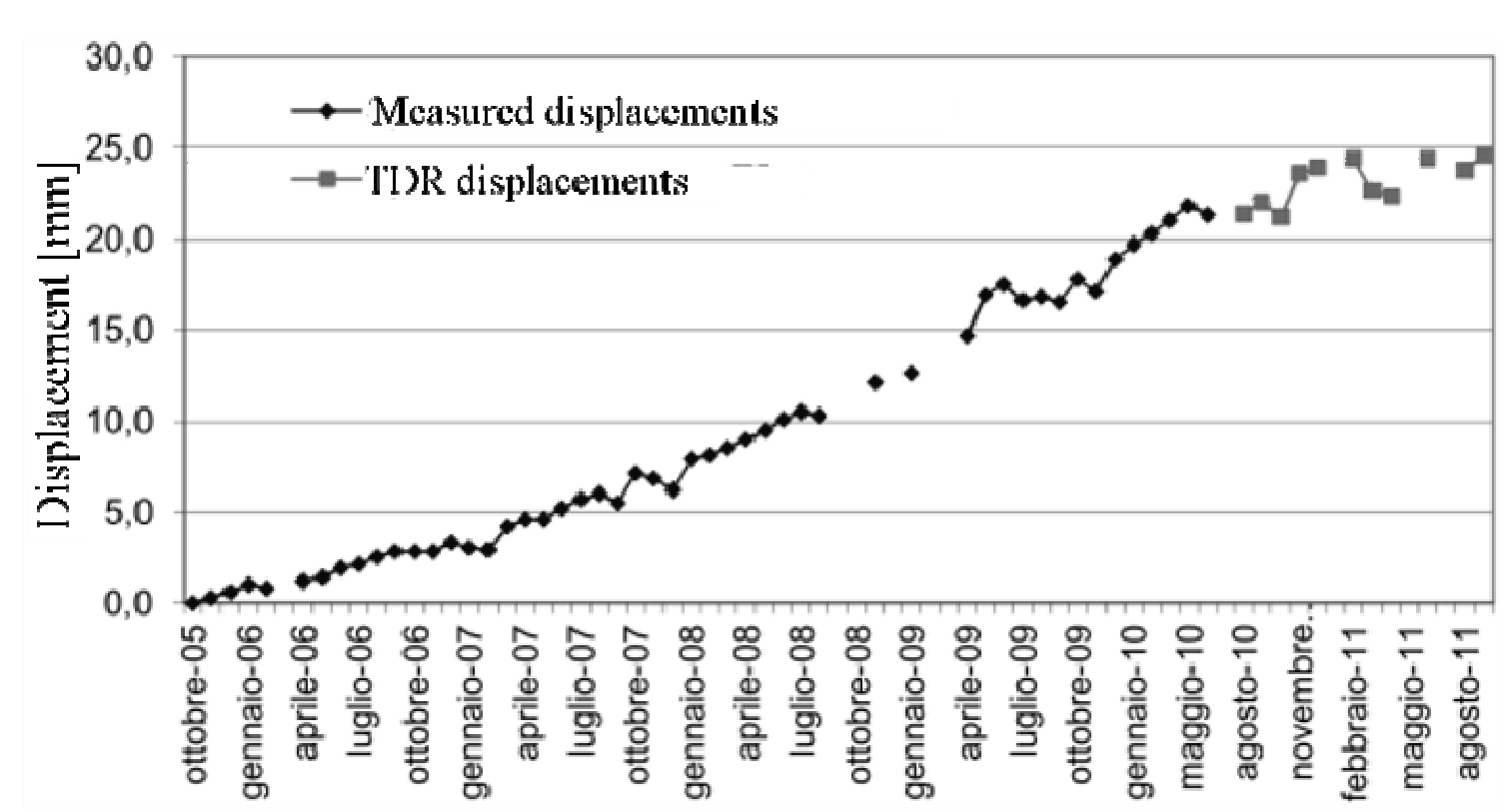

Figure 6. TDR and Inclinometric measurements.

TDR measures had to be discarded because evidently in contrast with other data, probably due to some operator errors. Laboratory tests indicated how is possible to overcome this issue performing various measures at the same time to average results.

It is also important to point out that each TDR cable follows a different calibration curve. According to this, it is not possible to extend the calibration of one TDRInclinometer couple to other TDR cables deployed across the same slope. The particular features of each cable are related to the grouting composition, the number of shear points, temperature and moisture conditions.

\section{CONCLUSION}

TDR laboratory testing was used to support the analysis of field data collected by a network of inclinometers and TDR cables installed on an unstable slope. Since signals collected by the TDR echo-meter may be influenced by several factors, we performed laboratory tests to find possible relationships between deformation values and the amplitude of the reflected signals. The linear behaviour proposed in the scientific literature was replaced by a parabolic law that better suits the collected datasets; this finding was applied to a real case database were coupled inclinometers and TDR cables permit to validate the findings. Nowadays, TDR technique can measure the depth where deformation occurs with high accuracy. However, if displacement value has to be estimated, a pairing and tuning period with a traditional inclinometer is needed to define the right correlation law between displacement and reflection amplitude. TDR is a very promising and effective technique for landslide monitoring but, at the present stage, it cannot be used as a standalone methodology when displacements have to be determined with high accuracy.

\section{REFERENCES}

[1]Dowding, C. H., Dussud, M. L., Kane, W. F., \& O’Connor, K. M. (2003). Monitoring deformation in rock and soil with TDR sensor cables. Geotechnical News, 21(2), 51-59. 
[2]Rohrig, J., (1931). Location of Faulty Places by Measuring with Cathode Ray Oscillographs, ELEKTROTECH Z., vol.8

[3]Dalton FN, Herkelrath WN, Rawlins DS, Rhoades JD; Time Domain Reflectometry: simultaneous measurement of soil water content and electrical conductivity with a single probe; Science; 224; 989-990; 1984;

[4]Dalton FN; Development of Time Domain Reflectometry for measuring soil water content and bulk soil electrical conductivity; Advances in Measurement of Soil Physical Properties: Bringing Theory into Practice; G. C. Topp et al., Eds., Soil Sci. Soc. Am., Madison, WI, SSSA Sp. Pub. 30; 143-167; 1992 ;

[5]Dowding $\mathrm{CH}$, Su MB, O'Connor KM; Principles of Time Domain

Reflectometry applied to measurement of rock mass deformation; Int. Journal of Rock Mechanics and Mineral Science; 25 (5); 287-297; 1988

[6]Dowding $\mathrm{CH}, \mathrm{Su} \mathrm{MB}$, O'Connor KM; Measurement of rock mass deformation with grouted coaxial antenna cables; Rock Mech. Rock Eng; 22; 1-23; 1989;

[7]Lord E., Peterson D., Thompson G., Stevens T. (1991). New technologies for monitoring highwall movement at Syncrude Canada Ltd; Preprint CIM/AOSTRA 91-97, paper presented at CIM/AOSTRA 1992 Technical Conference, Banff; April 21-24; 97-1 - 97-8

[8]Aston T., Bétournay M.C., Hill J.O., Charette F. (1994). Application for monitoring the long term behaviour of Canadian abandoned metal mines; Proceedings, Symposium and Workshop on Time Domain Reflectometry in Environmental, Infrastructure, and Mining Applications, Northwestern University, U.S. Bureau of Mines Special Publication SP-19-8-94; 518-527

[9]Dowding $\mathrm{CH}$, Huang FC; Telemetric monitoring for early detection of rock movement with Time Domain Reflectometry; Journal of Geotechnical Engineering, American Society of Civil Engineers;120 (8); 1413-1427; 1994;

[10]Longoni, L., Arosio, D., Scaioni, M., Papini, M., Zanzi, L., Roncella, R., \& Brambilla, D. (2012). Surface and subsurface non-invasive investigations to improve the characterization of a fractured rock mass. Journal of Geophysics and Engineering, 9(5), 461.

[11]Scaioni, M., Longoni, L., Melillo, V., \& Papini, M. (2014). Remote sensing for landslide investigations: An overview of recent achievements and perspectives. Remote Sensing, 6(10), 9600-9652.

[12]Kane W.F., Beck T.J., Anderson N.O., Perez H. (1996) Remote monitoring of unstable slopes using Time Domain Reflectometry; Presented at the Eleventh Thematic Conference and Workshops on Applied Geologic Remote Sensing; Las Vegas, Nevada

[13]Kane WF, Beck TJ; Advances in slope instrumentation: TDR and remote data acquisition systems; Field Measurements in Geomechanics; 5th International Symposium on Field Measurements in Geomechanics; Singapore; 101-105; 1999; 
$15^{\text {th }}$ International SGEM GeoConference on science and technologies in geology, exploration and mining.

[14]Kane WF; Monitoring slope movement with Time Domain Reflectometry; Geotechnical field instrumentation: applications for engineers and geologist ; 2000;

[15]O'Connor K.M., Dowding C.H. (1999) GeoMeasurements by Pulsing TDR cables and probes; CRC Press, Boca Raton 